\title{
Location of the Mesopontine Neurons Responsible for Maintenance of Anesthetic Loss of Consciousness
}

\author{
๑DAnne Minert, Shai-Lee Yatziv, and ${ }^{\circledR}$ Marshall Devor \\ Department of Cell and Developmental Biology, Institute of Life Sciences, and Center for Research on Pain, The Hebrew University of Jerusalem, Jerusalem \\ 91904, Israel
}

The transition from wakefulness to general anesthesia is widely attributed to suppressive actions of anesthetic molecules distributed by the systemic circulation to the cerebral cortex (for amnesia and loss of consciousness) and to the spinal cord (for atonia and antinociception). An alternative hypothesis proposes that anesthetics act on one or more brainstem or diencephalic nuclei, with suppression of cortex and spinal cord mediated by dedicated axonal pathways. Previously, we documented induction of an anesthesia-like state in rats by microinjection of small amounts of $\mathrm{GABA}_{\mathrm{A}}$-receptor agonists into an upper brainstem region named the mesopontine tegmental anesthesia area (MPTA). Correspondingly, lesioning this area rendered animals resistant to systemically delivered anesthetics. Here, using rats of both sexes, we applied a modified microinjection method that permitted localization of the anesthetic-sensitive neurons with much improved spatial resolution. Microinjected at the MPTA hotspot identified, exposure of 1900 or fewer neurons to muscimol was sufficient to sustain whole-body general anesthesia; microinjection as little as $0.5 \mathrm{~mm}$ off-target did not. The GABAergic anesthetics pentobarbital and propofol were also effective. The GABA-sensitive cell cluster is centered on a tegmental (reticular) field traversed by fibers of the superior cerebellar peduncle. It has no specific nuclear designation and has not previously been implicated in brain-state transitions.

Key words: anesthesia; arousal; MPTA; reticular formation; syncope; wet blanket hypothesis

Significance Statement

General anesthesia permits pain-free surgery. Furthermore, because anesthetic agents have the unique ability to reversibly switch the brain from wakefulness to a state of unconsciousness, knowing how and where they work is a potential route to unraveling the neural mechanisms that underlie awareness itself. Using a novel method, we have located a small, and apparently one of a kind, cluster of neurons in the mesopontine tegmentum that are capable of effecting brain-state switching when exposed to $\mathrm{GABA}_{\mathrm{A}^{-}}$ receptor agonists. This action appears to be mediated by a network of dedicated axonal pathways that project directly and/or indirectly to nearby arousal nuclei of the brainstem and to more distant targets in the forebrain and spinal cord.

\section{Introduction}

Transient loss of consciousness (LOC, "reversible coma") and the other components of the anesthetic state, immobility, analgesia and amnesia, are classically attributed to generalized pharmaco-

\footnotetext{
Received Feb. 26, 2017; revised Aug. 6, 2017; accepted Aug. 9, 2017

Author contributions: A.M. and M.D. designed research;A.M., S.-L.Y., and M.D. performed research; A.M., S.-L.Y., and M.D. analyzed data; A.M. and M.D. wrote the paper.

This work was supported by the Israel Health Ministry, the Seymour and Cecile Alpert Chair in Pain Research, the Willem Bean Legacy Fund, and the Hebrew University Center for Research on Pain. The funders played no role in the planning or execution of the experiments or the drafting of this manuscript. We thank Yelena Fishman, Adi Goldenberg, Tamir Avigdor, and Mark Baron for their contributions and Clif Saper and Jun Lu for helpful comments on the study and for hosting the senior author at BIDMC where the initial experiments were performed. The bonus time method as a means of improving spatial resolution was originally suggested by Clif Saper.

The authors declare no competing financial interests.

Correspondence should be addressed to: Prof. M. Devor, Department of Cell and Developmental Biology, Institute of Life Sciences, The Hebrew University of Jerusalem, Jerusalem 91904, Israel. E-mail: marshlu@mail.huji.ac.il.

DOI:10.1523/JNEUROSCI.0544-17.2017

Copyright $\odot 2017$ the authors $\quad 0270-6474 / 17 / 379320-12 \$ 15.00 / 0$
}

logical suppression of CNS function. Once ascribed to altered physical properties of lipid membranes, suppression is now known to be mediated by ubiquitous inhibitory ligand-gated ion channels, most prominently the $\mathrm{GABA}_{\mathrm{A}}$-receptor $\left(\mathrm{GABA}_{\mathrm{A}}-\mathrm{R}\right.$; Campagna et al., 2003; Franks, 2008). A refinement of this "generalized suppression" or "wet blanket" hypothesis adds that each component of anesthesia is realized in a distinct CNS structure. Thus, circulating anesthetic molecules suppress the neocortex and hippocampus to bring about LOC and amnesia and the brainstem and spinal cord to cause atonia and analgesia (Lukatch and MacIver, 1996; Antognini et al., 2003; Grasshoff et al., 2005; Hentschke et al., 2005; Bonhomme et al., 2012; Raz et al., 2014).

An alternative hypothesis holds that anesthetic molecules act at a focus from which they engage dedicated axonal pathways. The axons, in turn, project to the far-flung effector structures, from cortex to cord, inducing anesthesia secondarily. This "dedicated pathways" hypothesis originated with Moruzzi and Ma- 
goun, who suggested that anesthetics suppress the mesopontine ascending reticular activating system (aRAS) which, in turn, leads to cortical suppression and LOC (Bremer, 1936; Moruzzi and Magoun, 1949; French et al., 1953; Magni et al., 1959). Contemporary models parse the aRAS into numerous brainstem and diencephalic sleep-promoting and sleep-suppressing "arousal nuclei" with associated ascending and descending effector pathways. Anesthesia is induced when agents substitute for an endogenous neurotransmitter(s) in one or more nodes in this switching circuitry, "hijacking" network function. Proposals about where exactly this might occur include the locus coeruleus, tuberomammillary nucleus, medial thalamus, lateral hypothalamus, and preoptic area (Correa-Sales et al., 1992; Alkire et al., 2008; Franks, 2008; Lu et al., 2008; Brown et al., 2010; Moore et al., 2012; Zecharia et al., 2012; Scharf and Kelz, 2013; Anaclet et al., 2014; Baker et al., 2014; Weber et al., 2015).

A significant advance toward defining the locus of anesthetic action was the discovery that an anesthesia-like state is induced rapidly and reversibly by microinjecting $\mathrm{GABA}_{\mathrm{A}}-\mathrm{R}$ agonists into a circumscribed, bilaterally symmetrical region in the upper brainstem, the mesopontine tegmental anesthesia area (MPTA) (Devor and Zalkind, 2001; Voss et al., 2005; see video at http:// links.lww.com/AA/B466). This state closely resembles systemic anesthesia by behavioral, electrographic, and functional criteria and can be sustained by repeated microinjections (Sukhotinsky et al., 2007; Abulafia et al., 2009; Namjoshi et al., 2009; Devor et al., 2016; Sukhotinsky et al., 2016). Anesthesia comes on much too rapidly to permit drug diffusion to distant brain regions (seconds to a few minutes) and effective doses are far too small to survive dilution during vascular redistribution. These observations are therefore inconsistent with generalized CNS suppression, but they are compatible with the dedicated pathways hypothesis. In addition, we found that lesioning the MPTA renders animals resistant to anesthetic induction by the systemic route (Minert and Devor, 2016). The MPTA cluster may thus be singular. No comparable anesthetic-sensitive structure has been found despite systematic searching and, if another exists, engaging it is apparently insufficient because anesthesia cannot be induced in MPTAlesioned animals at clinically relevant doses. The intrinsic properties of MPTA neurons and their connectivity makes them both sufficient and necessary for GABAergic anesthetic induction (Sukhotinsky et al., 2016).

A limitation of our prior studies, however, is limited spatial resolution. MPTA microinjections through indwelling catheters likely exposed additional structures, including adjacent arousal nuclei, to the agonists. This is the reason that we chose to call the anesthetic-sensitive region an "area" without stipulating a specific nuclear designation. More precise localization of the relevant neurons is an important prelude to characterizing them in more detail and determining the mechanism whereby they switch brain and spinal cord state between wakefulness and anesthesia (Devor et al., 2016). With this aim in mind, we have implemented a modified drug delivery protocol with enhanced spatial resolution.

\section{Materials and Methods}

\section{Overview of the "bonus time" method}

Briefly, rats were anesthetized using the short-acting agent propofol and mounted in a stereotaxic instrument. Then, minute volumes of $\mathrm{GABA}_{\mathrm{A}}-\mathrm{R}$ agonists were microinjected unilaterally into the MPTA via a fine glass micropipette. We monitored the degree to which localized deposition of drug delayed the time to emergence from anesthesia ("anesthesia time") beyond what would have been expected without drug microinjection. Although maintenance of anesthesia is not identical to anesthetic induction, it is a reasonable surrogate in light of the fact that induction per se has already been documented after microinjection into the MPTA area during the awake state. Prolongation of anesthesia time is referred to here as a positive "bonus" and the approach is called "the bonus time" method.

\section{Animals and surgery}

Experiments were performed in two series using similar, but nonidentical methods. The first series, performed in the Department of Neurology, Beth Israel Deaconess Medical Center (BIDMC)/ Harvard University (Boston, MA) used adult male Sprague Dawley rats (270-330 g). In the subsequent series, performed at the Institute of Life Sciences, the Hebrew University of Jerusalem Israel (HUJI), we used adult female Wistarderived Sabra strain rats $(250-350 \mathrm{~g})$. At both venues, animals were maintained under specific pathogen-free conditions, $1-3$ per cage, room temperature $21-23^{\circ} \mathrm{C}, 12 \mathrm{~h}: 12 \mathrm{~h}$ day:night cycle, with lights on at 07:00. Food and water were available ad libitum. Experimental protocols were approved by the Institutional Animal Care and Use Committees of BIDMC and HUJI and, at both venues, they were conducted in accordance with the United States Public Health Service's Policy on Humane Care and Use of Laboratory Animals.

At BIDMC, a preliminary surgical procedure was performed to provide intravenous access for the main experiment. Under chloral hydrate anesthesia $(350 \mathrm{mg} / \mathrm{kg}$, i.p.), a sterile chronic indwelling catheter was introduced into the vena cava via a femoral vein tributary and firmly anchored to local fascia. The intravenous part of the catheter was made of soft silicone tubing. This was glued to a polyethylene tube (Intramedic PE50) that was tunneled under the skin and exteriorized at the back of the neck. Rats were given an analgesic postoperatively (Flunixin, $1 \mathrm{mg} / \mathrm{kg}$, s.c.) and were allowed to recover for $4-14 \mathrm{~d}$, at which time they underwent a terminal experiment in which drugs were microinjected into the MPTA. During the recovery time, catheters were flushed intermittently with heparin solution to help keep them patent. In experiments performed at HUJI, the previously implanted catheter for intravenous access was substituted by placing, on the day of the experiment itself, an indwelling neoflon catheter (26 G; Becton Dickinson) into the tail vein under brief isoflurane sedation.

At both venues, experiments began by anesthetizing the rat with a bolus dose of propofol (13 mg/kg, i.v., at BIDMC, propofol 1\%; Gensia Sicor Pharma; at HUJI, Propofol-Lipuro 1\%; B. Braun Medical). It was then mounted in a stereotaxic apparatus with head level between bregma and lambda and a small craniotomy was made over the MPTA target using a dental burr. At BIDMC, frontoparietal screw electrodes were placed bilaterally for recording EEG and a pair of needle electrodes were placed in the biceps femoris muscle to register the hindlimb EMG. The empirical endpoint used to mark the emergence from anesthesia was the sudden appearance of repetitive "pacing" movements of one or both hindlimbs. As soon as this was observed, animals were given a fixed supplemental dose of $10 \mathrm{mg} / \mathrm{kg}$ intravenous propofol to reinitiate anesthesia. This dose was determined in preliminary titration experiments to yield $\sim 15$ min of anesthesia before pacing reappeared. Pacing behavior served as a convenient and unambiguous marker of emergence. However, we also established that its onset was always accompanied by rhythmic bursts in the biceps femoris EMG (Fig. 1C), nocifensive response to hindpaw, and/or earlobe pinch. Slightly later theta waves $(4-8 \mathrm{~Hz})$ and sometimes higher-frequency EEG components $(15-30 \mathrm{~Hz})$ appeared, adding to and later replacing the prominent propofol-induced delta-band peak $(0.5-4.0 \mathrm{~Hz})$. In addition, in calibration trials in which the animal was released from the stereotaxic and the supplemental propofol postponed, we observed prompt return of righting. Having determined in this way that pacing reliably marks emergence from anesthesia, in subsequent experiments the behavioral endpoint was used as the primary marker of emergence. In particular, pinch stimuli were avoided until after pacing began because they are likely to accelerate emergence in an uncontrolled manner and introduce an element of experimenter bias.

After one or more supplemental intravenous injections of propofol at the fixed bolus dose, we began MPTA microinjections. The duration of anesthesia provided by the fixed bolus dose before commencement of drug microinjections was remarkably stable from trial to trial (Fig. 2) and served as a basis for determining whether drugs microinjected into the 

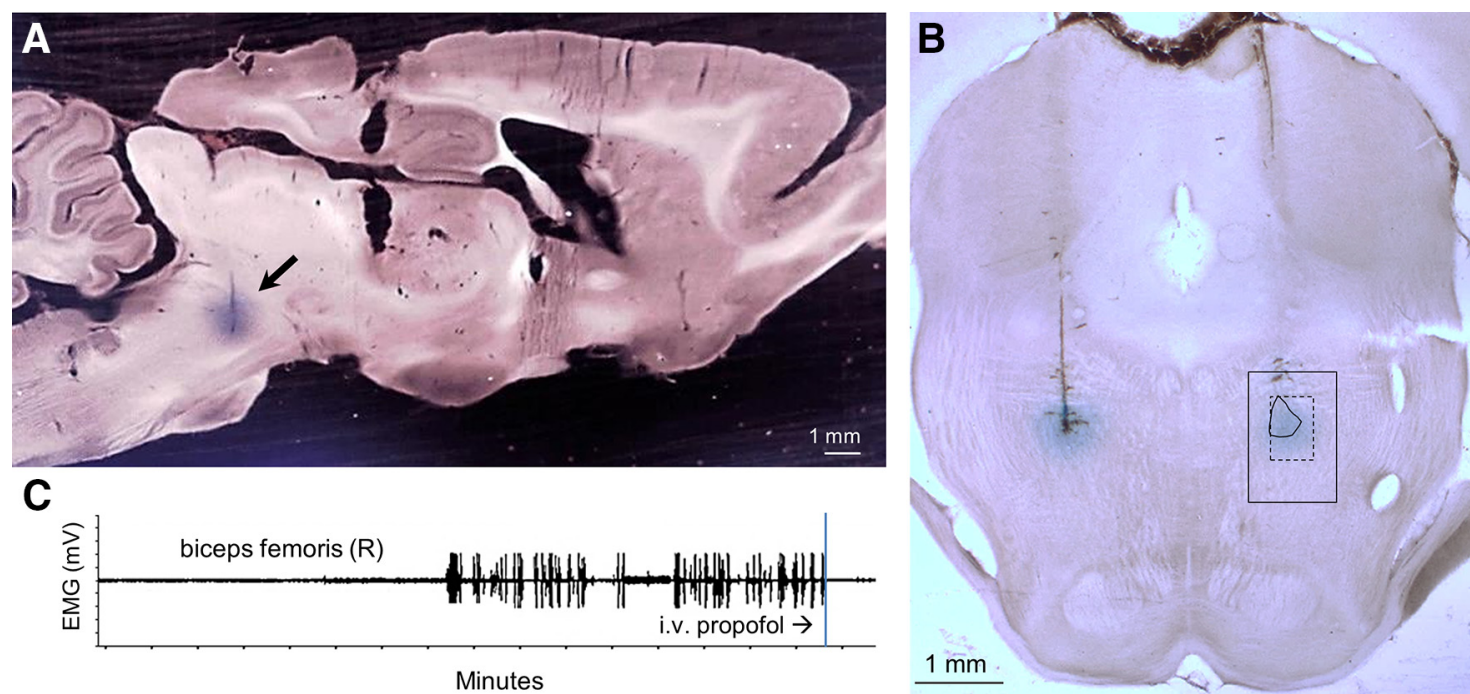

Figure 1. Microinjections of muscimol into the MPTA.A, Sagittal section showing the dye spread associated with a microinjection of $200 \mathrm{~nL}$ of muscimol into the MPTA. B, Coronal section showing the dye spread associated with on-target muscimol microinjections of $20 \mathrm{~nL}$, first on the left, then $20 \mathrm{~min}$ later on the right (rat \#340). These trials yielded bonus times of 10 and $21 \mathrm{~min}$, respectively. The boundaries of the MPTA as defined by Devor and Zalkind (2001) are overlaid on the right-sided microinjection (1000 $\times 1500 \mu \mathrm{m}$, solid outline). The common core of the MPTA is shown within the $500 \times 750 \mu \mathrm{m}$ dashed frame. C, The sudden appearance of repetitive hindlimb "pacing" movements was accompanied by rhythmic bursts in the biceps femoris electromyogram. Both were silenced by the standard intravenous bolus of propofol.

MPTA significantly extended the expected duration of anesthesia, providing a positive bonus time.

\section{MPTA microinjection}

Procedure. First, a micropipette pulled from fine borosilicate glass (inner diameter 0.3 or 0.5 mm (catalog \#B100-30-7.5HP or \#BF100-5015 , respectively; Sutter Instruments) with tip broken to a diameter $\sim 20-30 \mu \mathrm{m}$ was passed through the burr hole and dura and lowered to the level of the MPTA. In some experiments, we deliberately targeted nearby off-target locations. We began with relatively large microinjections (200 and $500 \mathrm{~nL}$ ) delivered to initial coordinates located within the boundaries of the MPTA as defined using the indwelling cannula method $(-7.6$ to $-8.8 \mathrm{~mm}$ caudal to bregma, $1.3 \mathrm{~mm}$ lateral to the midline, and 6.3$7.3 \mathrm{~mm}$ below the dura). Our strategy was to roam from there, progressively reducing the volume of drug microinjected, seeking a site(s) that provided a significant extension of anesthesia time. Once such a "hotspot" was found, additional small volume microinjections were placed rostrocaudal, mediolateral, and dorsoventral to effective site. Other trials targeted specific candidate nuclei including the pedunculopontine tegmental nucleus (PPTg), the parabrachial complex (PB), and the oral pontine reticular nucleus (PnO). All microinjections in this study were unilateral, favoring the left side, although to ensure bilateral symmetry, trials were also made on the right side.

Before insertion, microinjection pipettes were filled to several millimeters above the taper with one of the following test agents: muscimol (2 mм in saline; Sigma-Aldrich, Rehovot, Israel), pentobarbital $(200 \mathrm{mg} / \mathrm{ml}$; Pental, CTS, Kiryat Malachi, Israel), propofol (Propofol-Lipuro 1\%; B. Braun Medical, or 97\%, 2,6-diisopropylphenol; Sigma-Aldrich),
A
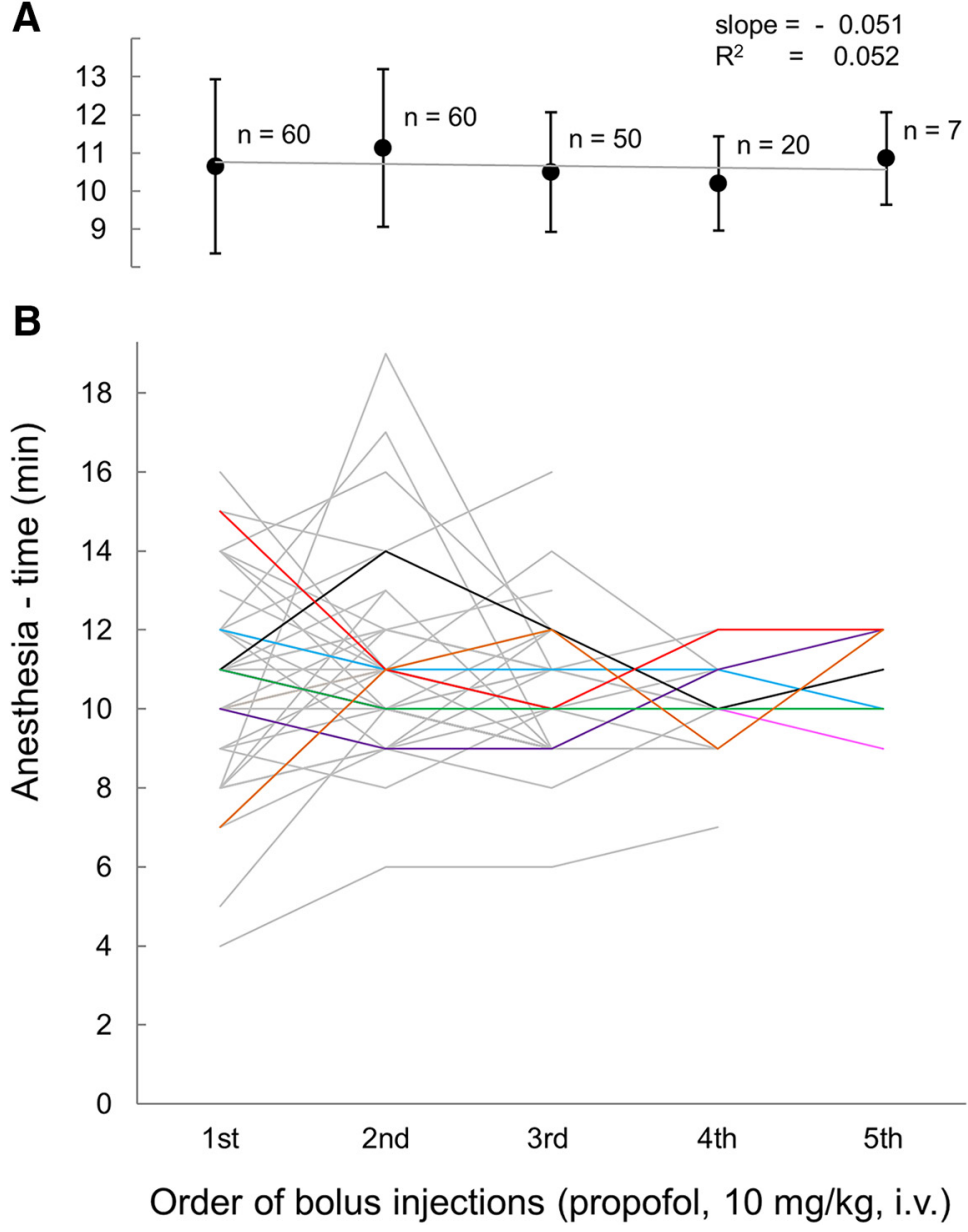

Figure 2. Anesthesia time was independent of the number of antecedent propofol boluses given. $A$, In rats given $2(n=60), 3$ $(n=50), 4(n=20)$, or $5(n=7)$ consecutive bolus doses of propofol mean anesthesia time was the same on the first bolus as on the $n^{\text {th }}$. $\boldsymbol{B}$, Lines represent anesthesia times of 60 individual rats upon repeated bolus dosing (all at HUJ). To ease separation, lines representing the seven rats given five consecutive doses are colored. Error bars in $\boldsymbol{A}$ indicate \pm SD. 
Table 1. Summary of muscimol microinjection trials showing venue, volume delivered, and bonus time obtained (in minutes, 91 trials in 53 rats)

\begin{tabular}{|c|c|c|c|c|c|c|c|c|c|c|c|}
\hline \multirow[b]{2}{*}{ BIDMC rat \# } & \multicolumn{2}{|l|}{$\begin{array}{l}500 \mathrm{~nL} \text { or } 200 \mathrm{~nL} \\
\text { bonus time }\end{array}$} & \multirow[b]{2}{*}{ HUJ rat \# } & \multicolumn{2}{|l|}{$\begin{array}{l}200 \mathrm{~nL} \\
\text { bonus time }\end{array}$} & \multicolumn{2}{|c|}{$\begin{array}{l}100 \mathrm{~nL} \text { or } 50 \mathrm{~nL} \\
\text { bonus time }\end{array}$} & \multicolumn{2}{|l|}{$\begin{array}{l}20 \mathrm{~nL} \\
\text { bonus time }\end{array}$} & \multicolumn{2}{|l|}{$\begin{array}{l}10 \mathrm{~nL} \\
\text { bonus time }\end{array}$} \\
\hline & Significant & NS & & Significant & NS & Significant & NS & Significant & NS & Significant & NS \\
\hline 4 & $65(R)$ & & 321 & & 1,2 & & & & & & \\
\hline 5 & & 13 & 358 & & & 10 & & & & & \\
\hline 6 & 35 & & 359 & & & $21(R)$ & & & & & \\
\hline 7 & $57(\mathrm{R})$ & & 322 & 26 & 5 & 35 & & & & & \\
\hline 8 & 39 & & 323 & 14 & & & & & & & \\
\hline 9 & 26 & & 324 & 36 & & 24 & & & & & \\
\hline 10 & 34 & & 325 & & & 10 & & & & & \\
\hline 11 & 22 & & 327 & 50 & & $23(\mathrm{R})$ & & & & & \\
\hline 12 & 50 & & 329 & 33 & $3(\mathrm{R})$ & 23 & & & & & \\
\hline 13 & 45 & & 370 & & & 9 & $2(R)$ & & & & \\
\hline 14 & & 10 & 371 & & & & $1,2(R)$ & & & & \\
\hline 15 & & 5 & 372 & & & & $5(R), 6$ & & & & \\
\hline 29 & 28 & & 330 & & & 32,34 & $2(\mathrm{R})$ & & & & \\
\hline 30 & 45 & & 331 & & & $22,46(\mathrm{R})$ & & & & & \\
\hline 31 & 45 & & 332 & & & $15,18(\mathrm{R})$ & & & & & \\
\hline 32 & 28 & & 338 & & & & $3,4(\mathrm{R}), 6,6(\mathrm{R})$ & & & & \\
\hline 33 & 36 & & 339 & & & & $1,4(R)$ & & & & \\
\hline 36 & 28 & & 351 & & & & $2(R)$ & & 3 & & \\
\hline \multirow[t]{5}{*}{37} & 28 & & 340 & & & & & $10,21(\mathrm{R})$ & & & \\
\hline & & & 341 & & & & & $18,30(\mathrm{R})$ & & & \\
\hline & & & 342 & & & & & & & 8 & \\
\hline & $500 \mathrm{~nL}$ or $200 \mathrm{~nL}$ & & 343 & & & & & $15,19,22(\mathrm{R})$ & & & \\
\hline & bonus time & & 345 & & & & & 11(R), 20 & & 18 & \\
\hline HUJ rat \# & Significant & NS & 346 & & & & & & & $16(\mathrm{R}), 19(\mathrm{R})$ & 5 \\
\hline 369 & 15 & & 347 & & & & & & & 30 & $4(\mathrm{R})$ \\
\hline 314 & 21 & 4 & 348 & & & & & $18,22(\mathrm{R})$ & & & \\
\hline 316 & 15 & 3 & 349 & & & & & & $3(\mathrm{R})$ & 31 & \\
\hline 317 & & $2,2,3$ & 350 & & & & & & $3(\mathrm{R})$ & & $1(\mathrm{R})$ \\
\hline 318 & 58,8 & 6 & 352 & & & & & & $4(\mathrm{R})$ & & 3 \\
\hline
\end{tabular}

Note that some rats had up to four microinjection trials. Scores marked (R) were from right-sided microinjections; italics indicate use of the volume set in italics. (riterion for statistical significance is described in the Materials and Methods. NS, Not significant.

lidocaine (5\% in PBS, prepared fresh from powder; Sigma-Aldrich), tetrodotoxin (TTX, $1 \mathrm{~mm}$ in artificial CSF; Alomone Laboratories), or saline $(0.9 \% \mathrm{NaCl})$. In most experiments, the solution microinjected included pontamine sky blue dye ( 1 or $2 \%$; Gurr/BDH Chemicals) to mark the microinjection site.

For microinjection, the butt of the pipette was attached by a length of polyethylene tubing to a valve apparatus that delivered pulses of positive air pressure. The pressure, duration, and duty cycle of the pulses were adjustable and were varied with tip diameter and solution viscosity to provide controlled extrusion of the test agent into the brain. Typically, we used pressure of $1 \mathrm{~kg} / \mathrm{cm}^{2}, 20 \mathrm{~ms}$ pulses, $1-10$ pulses/s. Between pulses, the back pressure on the pipette fell rapidly to zero. Calibrated volumes of test solutions, 500-10 nL, were microinjected by monitoring the change in the position of the meniscus inside the pipette using an ocular rule under optical magnification $(0.5 \mathrm{~mm}$ bore: $200 \mathrm{~nL} / \mathrm{mm}, 0.3 \mathrm{~mm}$ bore: $70 \mathrm{~nL} / \mathrm{mm})$. The volume per millimeter of internal pipette bore was calibrated previously using a 1 $\mu l$ Hamilton syringe.

Micropipettes were lowered to the target position and microinjection was initiated 1-3 min before the anticipated time of emergence of the animal from effects of the most recent intravenous bolus dose of propofol. Microinjection took $\sim 20-60 \mathrm{~s}$. The micropipette was left in place for 3-5 min after microinjection, but was withdrawn immediately if pacing began. Time was measured from the completion of the microinjection until hindlimb pacing began. If this equaled the anticipated emergence time (i.e., the time anticipated for the beginning of pacing), we registered a "bonus" of zero for that trial. If the time to pacing was greater than anticipated, then the difference was registered as a positive bonus, indicating prolongation of the duration of anesthesia. As soon as the bonus time was noted, an additional bolus dose of intravenous propofol was given. Animals were not allowed to awaken from anesthesia while restrained in the stereotaxic.

Evaluation of bonus time. In the first experiments, we established the anticipated time of emergence in each rat individually by averaging several cycles of fixed-dose intravenous propofol injections. The time from bolus injection until the beginning of pacing, "anesthesia time," proved to be stable with no consistent change over repeated cycles of bolus dosing within and across rats (Fig. 2). This justified a modification of the procedure such that, for each rat, we used the running average of (premicroinjection) anesthesia times obtained in all previous experimental trials. This value converged rapidly. Over 130 injection cycles (at HUJI), it averaged $11.0 \pm 2.0 \mathrm{~min}( \pm \mathrm{SD}$, coefficient of variation $=0.18 ; 42$ rats till \#359). This value remained stable over subsequent experiments with no detectable drift. Curiously, in experiments performed at BIDMC, anesthesia time after the identical bolus dose of propofol was significantly longer $[19.0 \pm 6.3 \mathrm{~min}$, coefficient of variation $=0.33$ ). The difference is $p<0.001,95 \%$ confidence interval $(\mathrm{CI})=7.1-9.5]$. Although this could be due to a variety of venue-specific factors, a likely factor is the use of male Sprague Dawley rats at BIDMC and female Sabra rats at HUJI. Clinical studies report significantly longer emergence times from propofol-induced anesthesia in men than in women when measurements begin at an equivalent anesthetic depth based on bispectral index values (Hoymork and Raeder, 2005; Choong et al., 2013).

In some experiments, only a single microinjection was given. In others, we gave more either at an adjacent location or when attempting to replicate a successful microinjection using a smaller volume (maximum of four microinjections in a single rat; Table 1). Follow-up microinjections were also given when, during the roaming process, muscimol yielded a short bonus time, when saline was delivered as a control, or when a novel 
drug was involved for which we wanted to verify that the microinjection had in fact been on target by follow-up delivery of muscimol or pentobarbital to the same locus.

\section{Histology}

Definition of the microinjection site. At the end of each experiment, as soon as pacing commenced, a final intravenous injection of propofol was given and the animal was rapidly killed by transcardial perfusion with $0.9 \%$ saline followed by $10 \%$ neutral $0.1 \mathrm{M} \mathrm{PO}_{4}$ buffered formalin $(\mathrm{pH}$ 7.3; Sigma-Aldrich), both at $37^{\circ} \mathrm{C}$. The brain was dissected out shortly after perfusion and postfixed at $4^{\circ} \mathrm{C}$ for at least $24 \mathrm{~h}$ in the same fixative. It was then transferred to $20 \%$ sucrose in PBS containing $0.02 \%$ sodium azide (PBS-azide) at $4^{\circ} \mathrm{C}$. At least $24 \mathrm{~h}$ later, tissue was cut on a freezing microtome into 50 - or $100-\mu \mathrm{m}$-thick coronal sections. We collected all sections in the region of microinjection beginning from the level at which the first pontamine dye spot was seen in the block face $\sim 200-300 \mu \mathrm{m}$ before dye actually appeared in sections and continuing until after dye was no longer present. Every third section through each dye spot was immediately mounted onto a glass slide in serial order. Intervening sections were saved in PBS-azide $\left(4^{\circ} \mathrm{C}\right)$. The number and relative location of individual dye spots seen on the block face as cutting proceeded always matched the microinjection protocol. The slides were air dried overnight, cleared with xylene, and coverslipped using Entellan (Merck). Tissue sections containing dye spots were optically projected onto the corresponding coronal level in the rat brain atlas of Paxinos and Watson (1998) and the magnification was varied until a best fit was obtained to the dorsal contour of the colliculi and the ventral contour of the pons. The maximal visible extent of the contour of the dye spot was then transferred by hand onto the atlas section by an individual blinded to microinjected drug, volume, and the experimental outcome. The maximal cross-section of each microinjection was measured planimetrically based on a section in which the micropipette tract emerged from the dye spot (Fig. 1A,B).

Estimation of drug spread. We estimated the extent of drug spread beyond the sphere defined by the volume microinjected based on the maximal dye-spread cross-section measured. The calculation assumed that spread was approximately isotropic and formed a sphere around the tip of the injection micropipette. This assumption was based on the fact that dye spots were round in both frontal and sagittal sections (Fig. $1 A, B)$. The radius $(r)$ of the droplet formed by drug solutions microinjected, before spread in the tissue, was calculated from the volume injected. For the smallest volumes used (e.g., $10 \mathrm{~nL}$ ), $r$ was taken as $134 \mu \mathrm{m}$, calculated by solving for $r$ in the formula for the volume of a sphere $V=$ $4 / 3 \pi r^{3}$. The radius of the sphere formed by dye spread after microinjection was based on the cross-sectional area of dye-spread measured, calculated by solving for $r$ in the formula for a circle, $A=\pi r^{2}$. The corresponding volume of spread was then calculated using $4 / 3 \pi r^{3}$.

Neuronal density. Estimating the number of MPTA neurons exposed to microinjected anesthetics requires a measure of neuronal density. Four naive rats were perfused as above and brains were cut in serial 50 $\mu \mathrm{m}$ frozen sections and immunolabeled for NeuN, a selective nuclear marker of viable neurons. Briefly, sections were incubated overnight in polyclonal mouse anti-NeuN antibody (Millipore catalog \#MAB377, $1: 25,000$, room temperature), followed by $1.5 \mathrm{~h}$ in secondary antibody (biotinylated goat anti-mouse IgG; Vector Laboratories, $1: 1000$; at $37^{\circ} \mathrm{C}$ ). Bound antibody was visualized using the $\mathrm{ABC}$ reaction and diaminobenzidine (Vectastain Elite ABC kit; Vector Laboratories).

One section from the mesopontine border (level -8.0 or $-8.3 \mathrm{~mm}$ relative to bregma; Paxinos and Watson, 1998) was selected for counting. The field of view was overlaid with a $1000 \times 1500 \mu \mathrm{m}$ counting frame representing the caudal MPTA (Fig. 1B) and all immunolabeled neurons within this region of interest (ROI) were counted bilaterally at $\times 250$ magnification using the Neurolucida system (version 10.51; MBF Bioscience) and their locations were plotted. Plotting began in an upper corner of the counting frame and proceeded systematically in a zig-zag manner one field of view at a time until the entire frame was covered. Cells on the edge of the ROI had to have $>50 \%$ of their area within the frame to be included in the count. The two counts (ROIs in the left and right MPTA) for each rat were averaged and these values were averaged over the four rats used. The average cell count per counting frame divided by the area of the counting frame provided neuronal density (neurons per square millimeter). This was converted to neurons per unit volume taking into consideration the section thickness of $50 \mu \mathrm{m}$. Therefore, the crude density in units of neurons per cubic millimeter was $20 \times$ the measured number of neurons per square millimeter. This crude density measure is an overestimate, however, because some neurons are split by the microtome blade and counted twice. To correct for this factor, we used Abercrombie's method (Koningsmark, 1970), which estimates the degree of overcounting based on section thickness $(50 \mu \mathrm{m})$ and mean neuronal diameter $(11.8 \mu \mathrm{m})$ based on a measured mean cell area of $109 \mu \mathrm{m}^{2}$ (see Results). The overcount was rectified by multiplying by the calculated correction factor $=0.83$.

Neuronal size and shape. Neurons within a smaller ROI that included a region we call the common core of the MPTA (see Results) were evaluated for soma size and shape. This ROI covered $25 \%$ of the area of the caudal MPTA counting frame $(500 \times 750 \mu \mathrm{m})$ and was separated from its upper, medial, and lateral borders by $250 \mu \mathrm{m}$ (Fig. 1B, dashed outline). Using the same sections as for neuronal counting, the perimeter of each neuron for which at least $50 \%$ of the soma area fell within the smaller ROI was traced with an on-screen cursor. From these measurements, Neurolucida calculated the somatic area and aspect ratio as follows: (min diameter) $\div$ (max diameter). As aspect ratio approaches 1 , the soma becomes less flat and more symmetric (e.g., circular or square). We also calculated the form factor as follows: $\left[(4 \pi \times\right.$ area $) \div\left(\right.$ perimeter $\left.\left.^{2}\right)\right]$, a parameter reflecting the tortuosity of the perimeter, and roundness as follows: $\left[(4 / \pi \times\right.$ area $\left.) \div(\text { maximum diameter })^{2}\right]$, a parameter reflecting the compactness of the soma, with a circle having a roundness of 1 .

\section{Statistical evaluation}

Expected duration of anesthesia after repeated fixed-dose bolus injections of propofol was based on the observed average anesthesia time \pm $\mathrm{SD}$ as described above. In light of the stability of anesthesia time after bolus injections of propofol (Fig. 2), it was possible to evaluate for individual microinjection trials whether anesthesia time was increased significantly; that is, whether the bonus time obtained was significantly greater than zero. In doing this, we applied a highly conservative criterion. Specifically, bonus time in a particular trial needed to be at least 3 SDs $>0$ to be declared statistically significant $(Z$-score $=3$, 1-tailed $p=$ $0.001)$. Therefore, the minimally significant bonus time was $18.8 \mathrm{~min}$ (BIDMC) and $6.1 \mathrm{~min}$ (HUJI). Differences between group means were evaluated using 2-tailed Student's $t$ tests after confirming normality of the underlying data distributions. Significance of linear regressions $\left(R^{2}\right)$ was tested using Pearson tests. The 95\% CIs were calculated using Medcalc (https://www.medcalc.org/calc/comparison_of_means.php). All means are given \pm SD except where use of SEM is noted.

\section{Results}

\section{Locating the MPTA}

A total of 91 unilateral muscimol microinjections, made in 53 rats, were targeted to the MPTA area and adjacent areas of interest (Table 1). We began with a few $500 \mathrm{~nL}$ microinjections to match the ones given in our prior studies using unilateral microinjections via chronically implanted cannulae (Devor and Zalkind, 2001; Devor et al., 2016). Then, we gradually reduced the volume to as little as $10 \mathrm{~nL}$ at each step, attempting to refine the boundaries of the effective area (Fig. $1 A, B$ ). The main result was identification of a small subregion within the originally defined MPTA area at which very small microinjections reliably extended anesthesia time, whereas closely adjacent microinjections did not.

Figure 3 shows the location of the injection centers of all 91 trials, where filled symbols indicate loci that yielded a significant bonus time and open symbols no bonus. The scatter of effective loci using volumes of $500-50 \mathrm{~nL}$ was strikingly larger than that using smaller volumes $(20-10 \mathrm{~nL})$. This is because, given the greater spread of drug associated with larger volumes, the center 


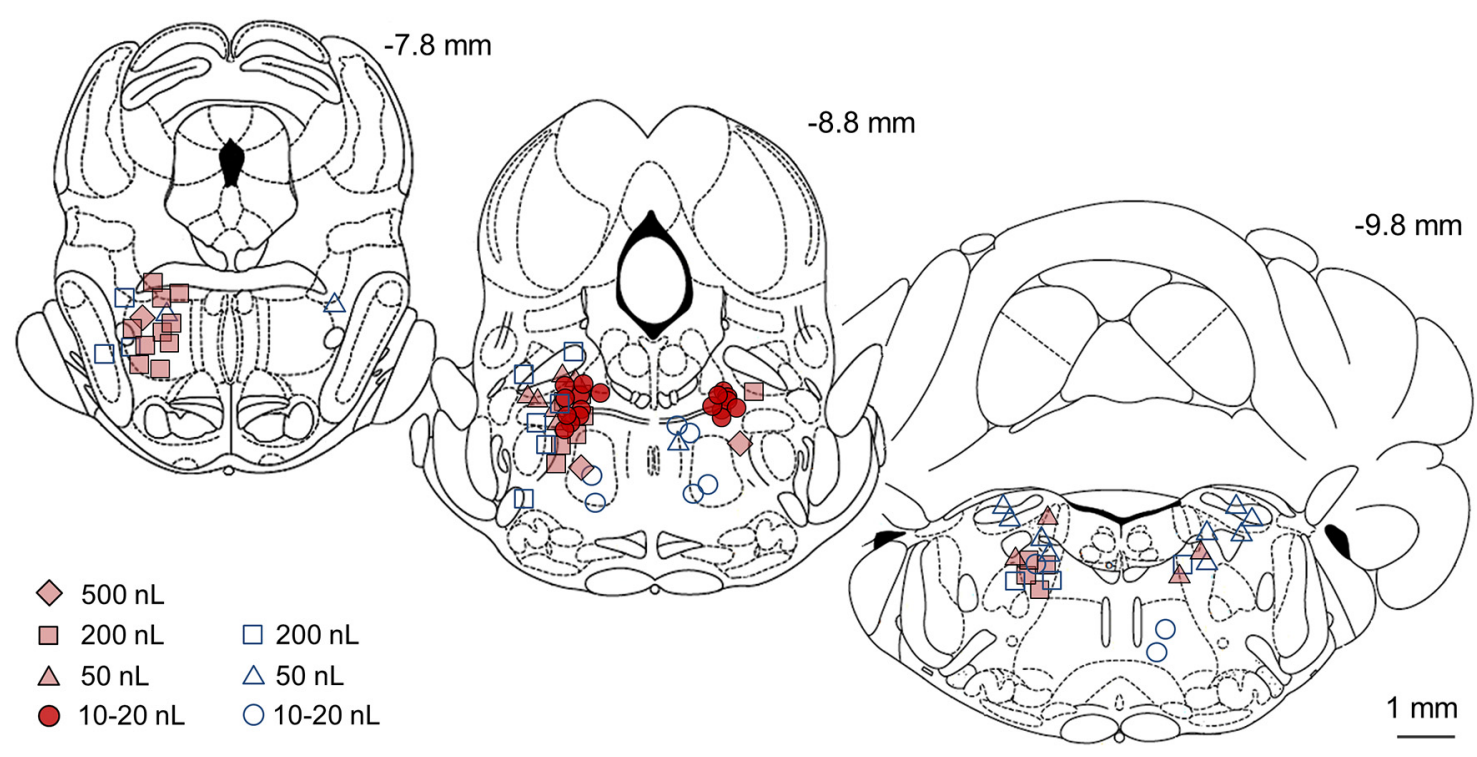

Figure 3. Small volume muscimol microinjections $(10-20 \mathrm{~nL})$ locate the hotspot for anesthetic induction within the MPTA area. Symbols mark centers of the microinjections listed in Table 1 , with the volume microinjected indicated for each symbol. Filled symbols indicate trials that yielded a significant bonus time; open symbols indicate bonus times that were not significant. Numbers above the coronal sections indicate the section's location caudal to bregma (in millimeters; outlines from Paxinos and Watson, 1998). Microinjections that fell on planes -7.0 to -8.0 are gathered on the most rostral section outline $(-7.8 \mathrm{~mm})$, those on planes -8.0 to -9.16 are gathered on the middle section $(-8.8 \mathrm{~mm})$, and those that fell on planes -9.3 to -10.8 are gathered on the caudal section $(-9.8 \mathrm{~mm})$. Many effective microinjections overlap, especially in the dark (red) clusters.

of effective microinjections could be farther from the effective cell cluster (hotspot). The loci of unsuccessful microinjections surrounded the central effective core in all three dimensions. The spatial spread of the pontamine sky blue dye used to track the microinjected muscimol was typically spherical with a tearshaped extension running vertically along the track of the micropipette used for injection (Figs. 1A,B,4). Plots of all 17 small volume (10 or $20 \mathrm{~nL})$ microinjections that were effective (i.e., which yielded a significant bonus) clustered in a bilaterally symmetrical region just ventral and lateral to the periaqueductal gray, at the far lateral edge of the decussation of the superior cerebellar peduncle (SCP) (Fig. 5A). The dye spread area of each of these microinjections is indicated in light pink in the figure, along with the core area common to all, which is dark red (left and right sides). Dye spread associated with the 14 microinjections centered on this plane that failed to yield a significant bonus surround this area (volumes $10-200 \mathrm{~nL}$; light blue diagonal lines). In only two of these ineffective trials was there likely to have been overlap with the common core area (rat \#15, $200 \mathrm{~nL}$ centered $-8.0 \mathrm{~mm}$ from bregma, and rat $\# 322,200 \mathrm{~nL}$ centered $-8.3 \mathrm{~mm}$ from bregma, both bonus times $=5 \mathrm{~min}$; Fig. $5 \mathrm{~A}$, left).

In contrast, in our original study in which relatively large $(\geq 500 \mathrm{~nL})$ microinjections were made through previously implanted guide cannulae, we logged failure to induce anesthesia in nearly half of trials (46\%) in which targeting appeared to be adequate. A number of technical causes for this were suggested (Devor and Zalkind, 2001). Here, we logged only two such failures (5.4\% of trials). We attribute the improvement to the better control of drug delivery afforded by the bonus time method and to the use of smaller, more focal microinjections. For example, it has been reported that muscimol delivered to the $\mathrm{PnO}$ promotes arousal (Xi et al., 2001; Watson et al., 2011). Large microinjections that exposed much of the PnO together with the MPTA might have attenuated effects obtained here using more focal MPTA microinjections.

Figure $5 B$ shows all 35 effective microinjections ( 23 rats, including the $50-500 \mathrm{~nL}$ microinjections). In 33 of the cases (94\%), the dye spread overlapped the common core area on the left and, in the remaining two, it approached very closely and in fact did include the mirror common core (right side). Hereinafter, the term "common core" will refer to the dark red region on the right side in Figure 5A. A number of effective microinjections using larger volumes had their centers rostral to the -8.0 plane or caudal to the -9.16 plane $(n=10$ and 8 , respectively; Fig. 3). Extrapolating based on dye spread radius (Myers, 1966; Myers and Hoch, 1978) in each case, the muscimol would likely have reached the common core. Overall, bonus times for the $n=37$ muscimol microinjections that included the common core averaged $25.1 \pm 14.0 \mathrm{~min}$, whereas bonus times of the $n=12$ surrounding microinjections that did not include the common core averaged $3.6 \pm 2.4 \mathrm{~min}$ (Table 1$)$. The difference is statistically significant $(p<$ $0.0001 ; 95 \%$ CI $=29.7-13.3$ ).

Microinjections that fell within the PPTg, the PB, and the $\mathrm{PnO}$, but in which the dye spread did not include the common core of the MPTA, failed to yield a significant bonus (PPTg: 4 rats, 4 trials, bonus $=3.0 \pm 1.8 ; \mathrm{PB}: 3$ rats, 6 trials, bonus $=4.2 \pm 3.1$ min; PnO: 3 rats, 5 trials, bonus $=3.2 \pm 1.0$ min; Figs. 3,4 ). A few microinjections, including these nuclei, did produce a significant bonus, but, in each one, the marker dye and presumably the muscimol, reached the MPTA common core (Fig. 3). Saline microinjections centered on the common core never yielded a significant bonus (10 trials in 5 rats, bonus $=2.6 \pm 1.1 \mathrm{~min}$, horizontal dark blue lines; Fig. 5 C).

The laterodorsal tegmental nucleus (LDTg) is another nearby nucleus implicated in sleep-wake regulation. No microinjections were restricted to the LDTg, but 13 fell in the MPTA without impinging on the LDTg and all of these yielded significant bonus scores. Together, these observations indicate that the functional hotspot of the MPTA region is not the PPTg, PB, PnO, or LDTg. In addition, except for the LTDg, for which data are not available, we can rule out the others as able to support anesthesia when exposed to muscimol. 


\section{Exposure of MPTA neurons to GABAergic anesthetic agents}

The MPTA area was originally discovered using systematic intracerebral microinjections of the barbiturate anesthetic pentobarbital (Devor and Zalkind, 2001). However, because muscimol is a direct $\mathrm{GABA}_{\mathrm{A}}-\mathrm{R}$ agonist, in contrast to pentobarbital, which acts at an allosteric modulatory site on the receptor (Löscher and Rogawski, 2012), and because it has a much higher affinity for the $\mathrm{GABA}_{\mathrm{A}}-\mathrm{R}$ than pentobarbital $\left(K_{\mathrm{D}}=2-10 \mathrm{nM}\right)$, muscimol was used here as a tool to refine the functional boundaries of the effective MPTA cluster (Beaumont et al., 1978; Davies et al., 1998; Johnston, 2014). Muscimol, however, does not cross the blood-brain barrier and is hence ineffective as a general anesthetic agent upon systemic administration. We therefore investigated whether neurons in the MPTA common core also respond to pentobarbital (Fig. 6B). Microinjected into the common core area, a significant bonus was obtained on each of the 7 trials using pentobarbital ( $n=6$ rats, mean bonus $=19.3 \pm 8.4 \mathrm{~min}$ ). Thus, accurately targeted pentobarbital sustained anesthesia for $\sim 20$ min at $\sim 1 / 4000^{\text {th }}$ of the systemic dose ( $\sim 15$ mg i.v. vs $4 \mu$ g microinjected).

In addition, we tested microinjected propofol, a second GABAergic anesthetic currently in wide clinical use. Propofol $1 \%$ was effective in 7 microinjection trials ( 4 rats, mean bonus $=12.3 \pm 3.1 \mathrm{~min}$ ) and probably also in 2 additional trials in a fifth rat (total 9 trials in 5 rats, $10.9 \pm 3.9$ min all at HUJI; Fig. $6 B$ ). Both trials in the fifth rat yielded bonus times of $6.0 \mathrm{~min}$, very close to our $6.1 \mathrm{~min}, p<0.001$ criterion. The short bonus times obtained despite use of a saturating concentration of propofol was probably due to rapid washout by the circulation and perhaps also to a particularly low affinity to the $\mathrm{GABA}_{\mathrm{A}}-\mathrm{R}$ isoform(s) expressed by the relevant MPTA neurons. With this in mind, we also tested $97 \%$ propofol, which would have washed out more slowly. Indeed, this significantly increased bonus times $(22.7 \pm 14.2 \mathrm{~min}, 3$ trials in 3 rats compared with $1 \%$ propofol, 9 trials in 5 rats, $t$ test, $p=0.035$; Fig. $6 B$ ). Rapid washout could explain why Voss et al. (2005) obtained only a partial effect with propofol using the indwelling cannula method (analgesia without LOC). Other contributing factors might have included suboptimal targeting or co-recruitment of nearby pro-arousal neurons by the relatively large volumes they microinjected $(1000 \mathrm{~nL})$.

\section{Critical mass of neurons and neuronal characteristics}

How many MPTA neurons need to be exposed to muscimol to extend anesthesia time significantly? An upper-limit estimate of this number can be derived from the number of neurons exposed by $10 \mathrm{~nL}$ microinjections, the smallest volume used in this study. The radius of dye marks associated with such microinjections (mean $=395 \mu \mathrm{m}$, based on 6 on-target microinjections) represents a volume of $0.26 \mathrm{~mm}^{3}(260 \mathrm{~nL})$. Because the sphere radius of $10 \mathrm{~nL}=134 \mu \mathrm{m}$, the linear spread was $\sim \times 3$ in each dimension (volume spread is $\times 26$ ). Average neuronal density within the MPTA counting frame based on NeuN-labeled histological sections was $\sim 435$ neurons $/ \mathrm{mm}^{2}$ (Fig. $7 B$ ). This converts to $\sim 7200$ neurons $/ \mathrm{mm}^{3}$ after correcting for double counting of split cells using Abercrombie's formula (Koningsmark, 1970). Muscimol and the marker dye are both small, water-soluble molecules (m.w. $=114$ vs 992). Assuming that the spread of muscimol and the marker was approximately the same $\left(0.26 \mathrm{~mm}^{3}\right)$, up to $\sim 1900$ neurons would have been exposed to the drug by a $10 \mathrm{~nL}$ microinjection. The actual number is probably less (see Discussion).

The spherical volume associated with the MPTA common core is considerably smaller than the dye-spread volume from 10 $\mathrm{nL}$ microinjections. It has a radius of $0.22 \mathrm{~mm}$ and a spherical volume of $0.04 \mathrm{~mm}^{3}$ (40 vs $260 \mathrm{~nL}$; Fig. $5 B$, right). This volume contains only $\sim 300$ neurons. It is unclear whether it would suffice to expose the common core neurons alone to muscimol to obtain a significant bonus and clinical anesthesia. Microinjections smaller than $10 \mathrm{~nL}$ that do not spread beyond the common core will be required to answer this question. However, it appears that inclusion of the common core neurons is important, if not absolutely necessary. Specifically, there were three microinjection trials (Fig. 5A, left, blue diagonal lines) in which muscimol reached 

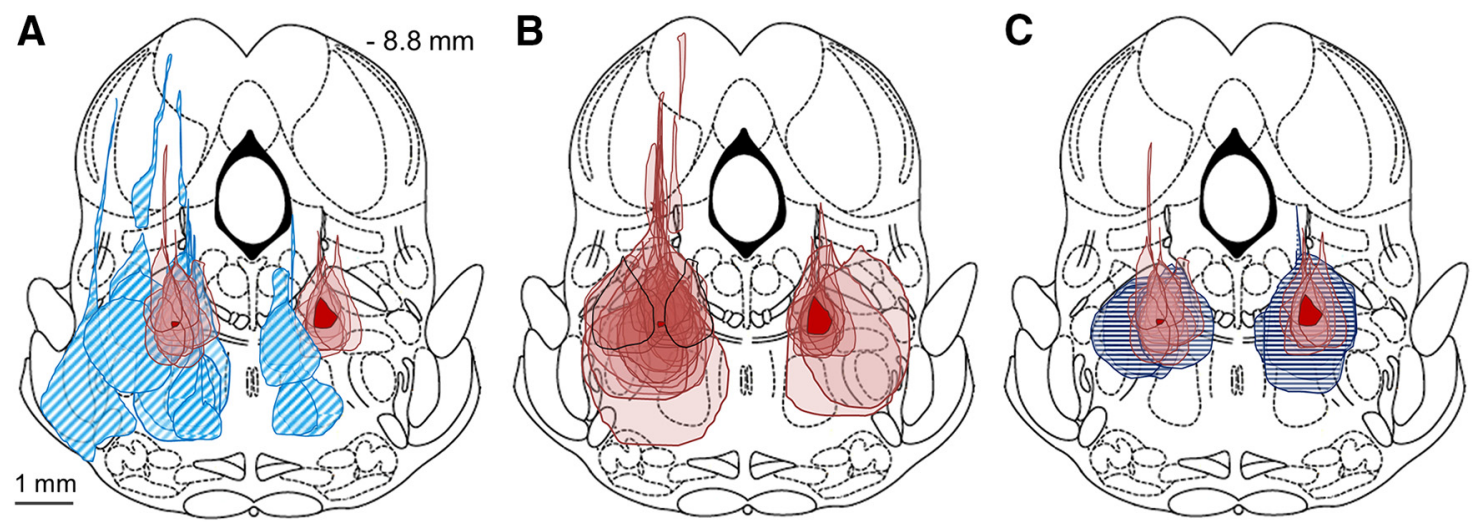

Figure 5. Location of the MPTA common core. $\boldsymbol{A}-\boldsymbol{C}$, Maximal cross-sectional area of effective (solid pink) and noneffective (hatched blue) microinjections are collected onto a single rostrocaudal plane $(-8.8 \mathrm{~mm})$. The track of the injection pipette in these trials actually lay over the range of -8.0 to $-9.16 \mathrm{~mm}$ caudal to bregma. $A$, Dye spread for the $17 \mathrm{small}$ effective muscimol microinjections largely overlap ( 10 or $20 \mathrm{~nL}, 9$ rats, 10 on the left and 7 on the right). The region in common to all (intersection), on the right and on the left, is shown in solid red (dark). The term "common core" refers to this area on the right. Noneffective microinjections ( $10-200 \mathrm{~nL}$ ) surround the effective ones (14 microinjections in 12 rats). $B$, As in $A$, but showing areas of both large and small effective muscimol microinjections (24 left, 11 right in 23 rats). Noneffective trials are not shown. The solid red area on the right is common to all 11 microinjections on that side. The (smaller) solid red area on the left is common to 22 of the 24 left-sided microinjections. Dye spread areas of the two microinjections not included fell closely nearby (black outlines, rats \#322 and \#15, 50 and $200 \mathrm{~nL}$, respectively). C, Dye spread areas of 10 saline (control) microinjections ( $5 \mathrm{rats} ; 50-200 \mathrm{~nL}$; horizontal dark blue lines) overlapped the common core zone bilaterally (5 left, 5 right). None of these yielded a significant bonus time.

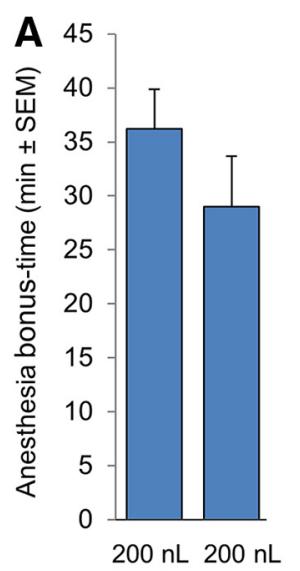

(ठ) (ㅇ)

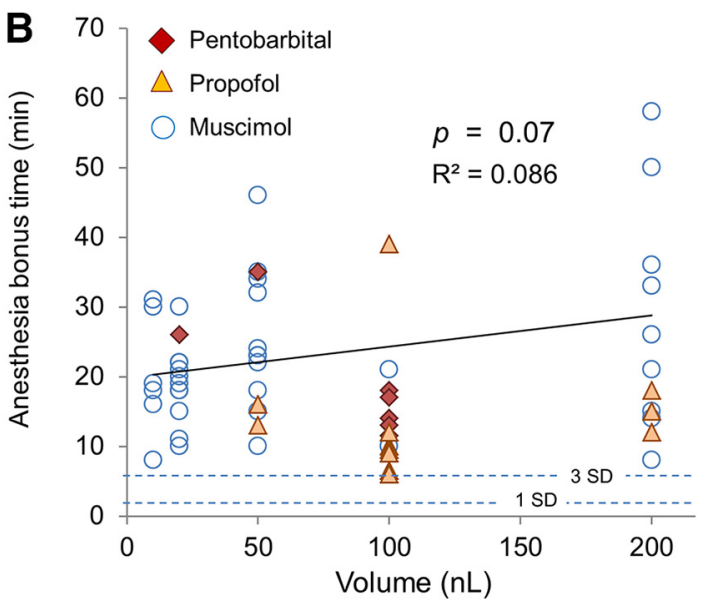

Figure 6. $A$, Average of the significant bonus times was the same $(p=0.24)$ at the two experimental venues (left: BIDMC, male Sprague Dawley rats; right: HUJI, female Wistar-derived Sabra rats). $\boldsymbol{B}$, Anesthesia bonus time did not correlate significantly with the volume (and thus dose) of muscimol microinjected (open circles; 39 trials in which there was a significant bonus; $R^{2}=0.086, p=0.07$ ). The regression line for this relation is shown. Also shown are bonus times obtained for on-target microinjections of pentobarbital ( 7 trials in 6 rats, filled diamonds) and propofol ( 12 trials in 9 rats, filled triangles). The regression of all bonus times on volume microinjected also failed to reach statistical significance $\left(R^{2}=0.011, p=0.43\right)$. All data shown were from experiments performed at HUJl. Horizontal dashed lines indicate the degree of variability of anesthesia times obtained using the standard bolus dose of propofol in trials in which there was no drug microinjection $(+1 \mathrm{SD}=2.0 \mathrm{~min} ;+3 \mathrm{SDs}=6.1 \mathrm{~min})$.

neurons in the effective zone (pink), but missed the common core (Fig. 5A, left, red). These trials failed to induce a significant bonus. Conversely, two microinjections that induced a significant bonus (Fig. 5B, left) hit the pink area, but missed the common core.

Given the ambiguity as to whether common core neurons are sufficient and/or essential, we examined the relation between the volume of muscimol microinjected and the bonus time obtained. For successful microinjection trials, bonus values varied considerably, averaging in the range of $20-30 \mathrm{~min}$. This was much longer than the anesthesia time provided by our standard intravenous bolus dose of propofol (11 min). However, interestingly, bonus values did not vary systematically with the volume microinjected and thus with the overall muscimol dose or the number of MPTA area neurons exposed to the drug (Fig. 6B). This was so even for individual rats that received microinjections of several volumes. For example, in 3 rats that received 2 muscimol microinjections at the same location, 200 $\mathrm{nL}(45.6 \mathrm{ng})$ and later $50 \mathrm{~nL}(11.4 \mathrm{ng})$, bonus scores obtained were 26 and 35 min, 36 and $24 \mathrm{~min}$, and 33 and $23 \mathrm{~min}$, respectively (Table 1 ). Likewise, bonus time values did not differ despite numerous differences at the two venues where the experiments were performed (Fig. $6 A$ ). This suggests that as long as the neurons in the common core (and perhaps a limited area beyond) are exposed to muscimol, there is little further effect of exposing a much larger number of neighboring neurons to the drug.

Neurons residing in the common core area vary in size and shape. Although most had a somatic area $<220 \mu \mathrm{m}^{2}(90 \%)$, there was a significant population of much larger size extending up to $1080 \mu \mathrm{m}^{2}$ (Fig. 7A,B). Interestingly, projection neurons, MPTA neurons retrogradely labeled from a variety of projection targets (Reiner et al., 2008), are considerably larger than the average (188 vs $109 \mu \mathrm{m}^{2}$ ). MPTA common core neurons were also heterogeneous in aspect ratio, form factor, and roundness (Fig. $7 C-E$ ). In addition to their size, the larger cells tended to be flatter (smaller aspect ratio and form factor) and had a more tortuous circumference (lower roundness) than the smaller cells. A considerable amount is known about the afferent and efferent connectivity of neurons in the MPTA area and on other cellular characteristics (Sukhotinsky et al., 2016), but further analysis is needed with respect to the MPTA's common core.

\section{Silencing MPTA neurons by exposing them to local anesthetics}

The GABAergic agents tested generally suppress activity in neurons that bear $\mathrm{GABA}_{\mathrm{A}}-\mathrm{Rs}$. In previous microinjection studies 

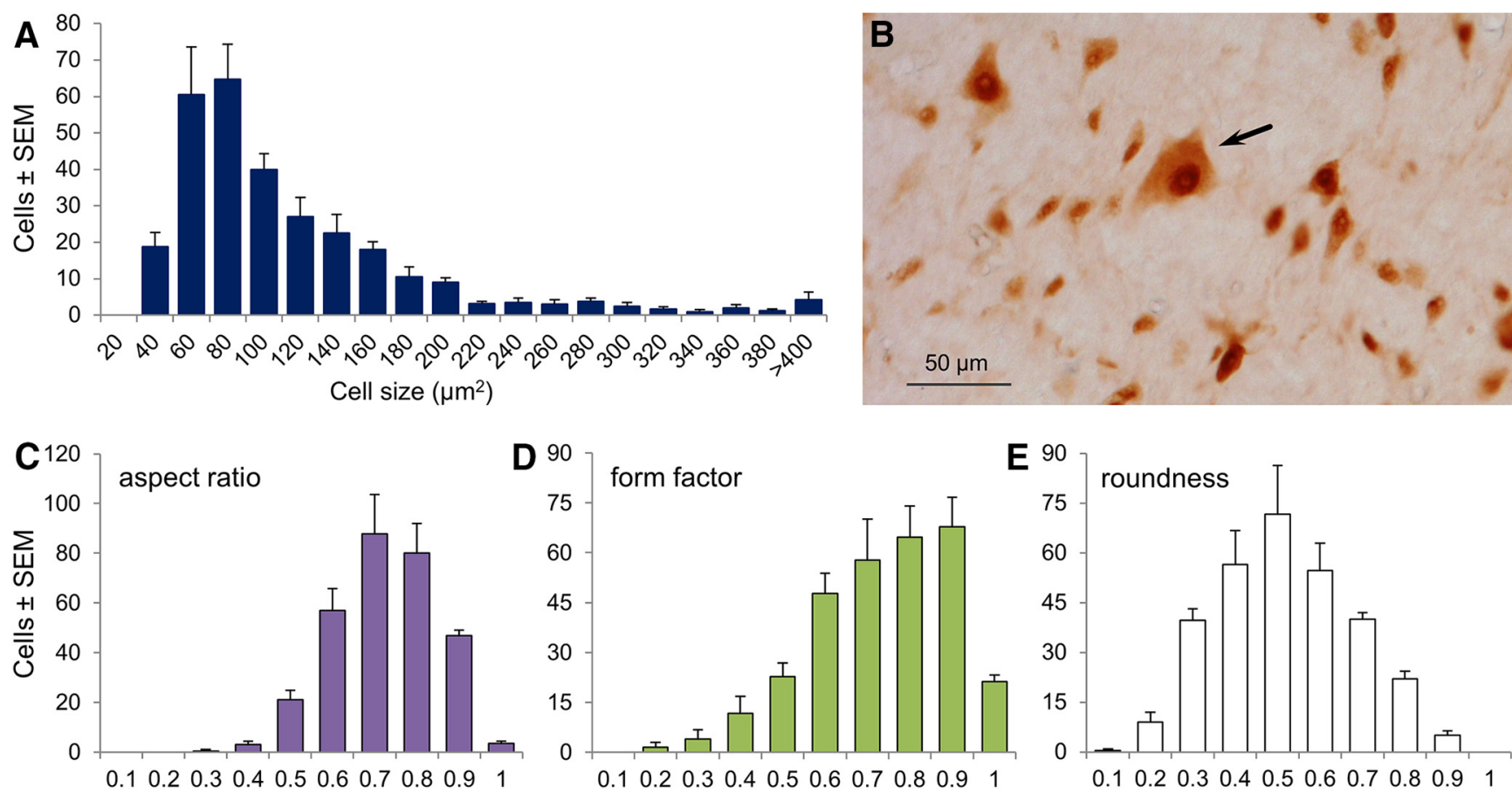

Figure 7. Sizes and shapes of neurons populating the MPTA common core are heterogeneous. A total of 1198 neurons were measured bilaterally in four naive rats. $\boldsymbol{A}$, Histogram showing somatic area. $\boldsymbol{B}$, Photomicrograph showing a typical field of NeuN-immunolabeled neurons, includes one neuron that is exceptionally larger (arrow). $\boldsymbol{C}-\boldsymbol{E}$, Histograms showing the distribution of three shape parameters in the population of neurons shown in $\boldsymbol{A}$. These were as follows: aspect ratio (a measure of flatness and radial symmetry), form factor (a measure of the complexity of the somatic perimeter), and roundness.

using the indwelling cannula method, we showed that delivery of lidocaine, a pan-sodium channel blocker that is expected to silence MPTA neurons nonselectively, does not induce anesthesia. This unexpected result is important because it constrains the mechanism by which the MPTA might influence the brain-state switching network (Devor and Zalkind, 2001; Devor et al., 2016). For this reason, we attempted to replicate this experiment using the new bonus time method. Indeed, on-target microinjection of $200 \mathrm{~nL}$ of $5 \%$ lidocaine yielded a nonsignificant bonus in each of 9 trials ( 9 rats, all at BIDMC, bonus $=2.7 \pm 5.8 \mathrm{~min}$ ). Finally, because lidocaine action is $\mathrm{pH}$ sensitive and we could not measure the in situ $\mathrm{pH}$ in the MPTA, we repeated this experiment with $1 \mathrm{~mm}$ TTX. Again, no significant bonus was obtained (4 trials in 2 rats, all at HUJI, $3 \times 50 \mathrm{~nL}, 1 \times 100 \mathrm{~nL}$, all on-target, mean bonus time $=1.0 \pm 1.8 \mathrm{~min}$ ).

\section{Discussion}

The original borders of the MPTA were set by framing the centers of effective microinjections (Devor and Zalkind, 2001). Agent spread was not taken into account. The bonus time method, with its improved spatial resolution, permitted a significant upgrade in our ability to define the actual location of the MPTA neurons that mediate general anesthesia upon exposure to GABAergic anesthetics. Relatively large $(\geq 200 \mathrm{~nL})$ muscimol microinjections at a distance from the MPTA common core yielded significant bonus times, but the effect was lost using smaller volumes. A progressive search using ever smaller volumes yielded a dorsal region in the caudal half of the (original) MPTA frame, where as little as $10 \mathrm{~nL}$ of muscimol reliably prolonged anesthesia time. Deviation by as little as $0.5 \mathrm{~mm}$ in any direction eliminated the effect. In a recent complementary experiment, we showed that bilateral MPTA lesions markedly reduced sensitivity to systemic GABAergic anesthetics (Minert and Devor, 2016). Impor- tantly, the territory common to all effective lesions was centered on the common core hotspot for anesthetic induction identified in the present study.

\section{Size and location of the MPTA}

Size

From knowledge of neuronal density and the extent of agent spread, we estimated that unilateral exposure of $\sim 1900$ MPTA neurons to muscimol is sufficient to maintain anesthesia for $10 \mathrm{~s}$ of minutes. This number is probably an overestimate. The marker dye, although somewhat larger than muscimol, had $1-2 \mathrm{~h}$ to diffuse, the typical time from microinjection to perfusion. The drug itself, in contrast, had to act within $\sim 2-3$ min to prevent pacing and termination of the trial. This brief diffusion interval would probably have permitted the drug to access $<1900$ neurons. If exposure of common core neurons is sufficient, then the minimal number could be as few as $\sim 300$ neurons. Concerning the overall size of the MPTA, we adopt the conservative position that GABA-receptive MPTA neurons involved in brain-state switching might be present wherever small-volume trials were successful (Fig. 8, right, pink zone). We refer to this as the "maximal MPTA" (mMPTA). With an equivalent radius of $0.75 \mathrm{~mm}$ (volume $=1.77 \mathrm{~mm}^{3}$ ), it contains $\sim 11,700$ neurons

\section{Nuclear designation}

In the authoritative rat brainstem atlases of Paxinos and Watson (Paxinos and Watson, 1998; Paxinos et al., 1999), the MPTA common core occupies a tegmental (reticular) field traversed by fibers of the SCP that has no nuclear designation. Common core neurons lie interstitial to the SCP. The larger mMPTA is likewise undesignated; the region ventral to the SCP is simply labeled "subpeduncular tegmentum." The mMPTA merges ventrally with the PnO and is laterally and caudally adjacent to the PPTg, 


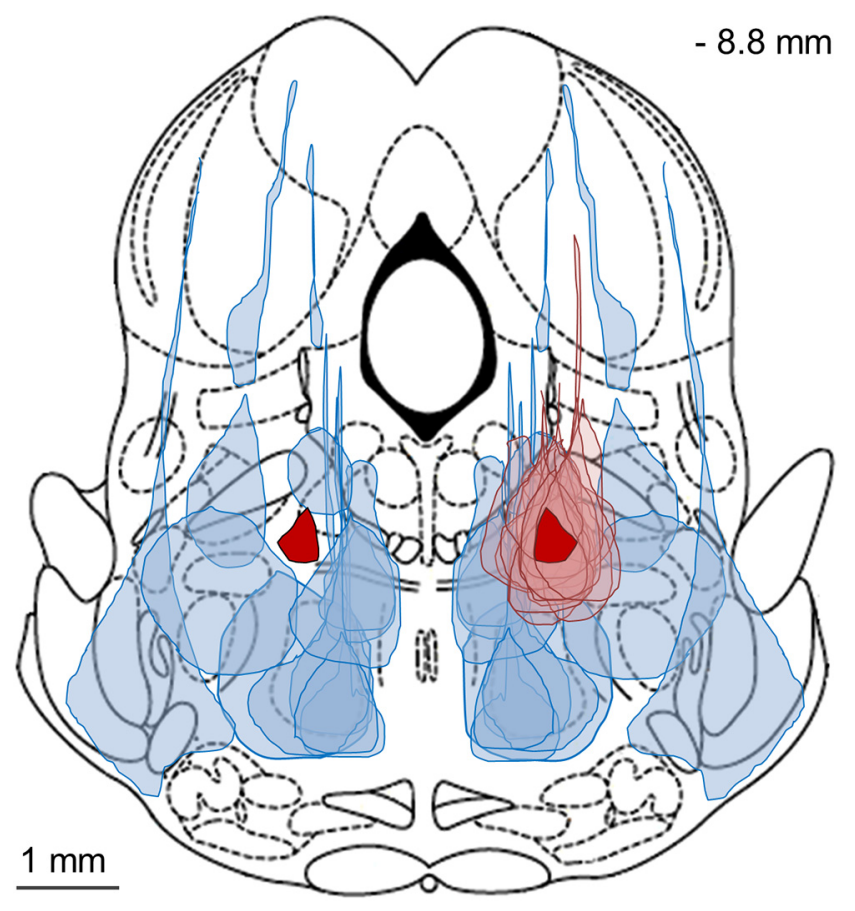

Figure 8. Graphical illustration of the MPTA common core and mMPTA. Left, Noneffective microinjections from the right side of Figure $5 A$ are mirror transposed and plotted together with noneffective microinjections actually made on the left side in Figure $5 A$ (light blue shading). These contours surround the transposed MPTA common core (Fig. 5A, right). Note the nonshaded halo surrounding the common core that is devoid of failed microinjections. Right, Dye spread areas of noneffective microinjections of all volumes (light blue shading) have been mirror transposed and combined with all of the effective small volume microinjections (10-20 nL; Fig. 5A, both sides, pink fill). The union of these pink contours is the MMPTA. The successful microinjections (pink) are surrounded on all sides by failed microinjections (blue). For clarity, the two negative trials noted in the Results that included the common core, whereas indicated on the right side in this illustration, are absent on the left.

caudally adjacent to the PB, and medially adjacent to the LDTg. These nuclei are implicated in sleep and arousal (Fuller et al., 2011; Watson et al., 2011; Roeder et al., 2016), but all were ruled out as the location of the anesthesia-promoting MPTA neurons. The mMPTA approximately overlaps the rodent homolog of the "mesencephalic locomotor region" (Sherman et al., 2015), an area in which Shik et al. (1969) documented (in cats) that electrical stimulation triggers locomotion. This is also the region where direct application of teflurane or cyclopropane were shown to induce sedation and sleep (in cats; Folkman et al., 1968). It contains neurons that send ascending and descending axons to nearby arousal nuclei and to more distant forebrain, hindbrain, and spinal cord structures associated with arousal, memory, movement, and pain. These pathways are presumably the effectors of the canonical components of anesthesia. A subset of neurons in the MPTA are known to express $G_{A B A}-R$ subunits. These are presumably the neurons that are sensitive to GABAergic anesthetics (Sukhotinsky et al., 2003, 2007, 2016).

\section{Indwelling cannula versus bonus time methods}

Both the original indwelling cannula method and the bonus time method permit focal deposition of $\mathrm{GABA}_{\mathrm{A}}-\mathrm{R}$ agonists in the brain. A major difference is that, using the former, anesthetic induction begins from the awake state; in the latter, the animal is already anesthetized (with propofol). Effective drugs prolong anesthesia time, postponing emergence, but they do not actually cause induction. This difference is potentially significant because emergence from anesthesia might be an active process, not simple reversal of induction as the anesthetic agent dissipates (Sleigh et al., 2001; Kelz et al., 2008). A variety of actions promote arousal and emergence from anesthesia. Noxious peripheral input (e.g. by tail pinch) is a prime example. Reanimation can also be evoked by activation of central pain pathways (Schiff et al., 2007; Brischoux et al., 2009; Anaclet et al., 2014; Roeder et al., 2016; Taylor et al., 2016; Morales and Margolis, 2017). It is not clear whether arousal by pain-provoking stimuli is mechanistically linked to mesopontine sleep-wake and anesthesia circuitry or is more general in nature. Either way, MPTA neurons appear to be key players in induction as well as emergence as between the two experimental methods both have been documented. Whether the same individual MPTA neurons contribute to both remains uncertain. Also uncertain is the degree to which our findings apply to anesthesia using non-GABAergic agents and to what extent they apply to clinical anesthesia in humans.

Finally, we confirmed our earlier observation that nonselective suppression of the MPTA using lidocaine (and now TTX) do neither. Our explanation of this apparent paradox is in a proposed model of anesthetic induction by MPTA neurons (Minert and Devor, 2016; Devor et al., 2016).

\section{Network actions}

Observations, mostly based on noninvasive imaging in humans, have highlighted large-scale network connectivity and top-down processing as central factors in conscious awareness, with thalamocortical interactions taking center stage (Brown et al., 2010; Bonhomme et al., 2012; Vijayan et al., 2013; Hudetz and Mashour, 2016; Tononi et al., 2016; Mashour and Hudetz, 2017). Degradation and recovery of effective connectivity are striking correlates of anesthetic induction and emergence. These observations, however, do not bear directly on the question of where in the brain anesthetics act. The temporal resolution of the BOLD signal is too low to discriminate generalized suppression by circulating drugs from activation of dedicated axonal pathways. In principle, both are capable of mediating the observed changes. Magnetoencephalography might have the required temporal resolution.

$\mathrm{GABA}_{\mathrm{A}}$ - $\mathrm{Rs}$ are ubiquitous in the CNS, including in the cerebral cortex, and they are surely engaged by circulating agonists. Our microinjection results, however, suggest that their engagement is not necessary for anesthetic LOC. It is probably also not sufficient because, after MPTA lesions with the thalamus and cortex intact, clinically relevant drug doses no longer induce anesthesia (Minert and Devor, 2016). We cannot exclude the possibility that certain parameters thought to be bona fide neural correlates-of-consciousness are not in fact causal, as they require direct agonist binding to cortical receptors. These could include anesthetic-induced reduction in cortical blood flow and metabolism, aspects of cortical connectivity, and some features of altered EEG. We note, for example, that bolus doses of systemic propofol induce burst suppression, but agonists microinjected into the MPTA, even at very high concentrations, do not (Devor et al., 2016). Assuming that in clinical (systemic) anesthesia MPTA-driven changes are engaged in addition to generalized suppression-driven changes, it will be important moving forward to unravel which changes are due to which process. This is true for both the cortical correlates of LOC and for the sensory and motor changes that accompany anesthesia, typically attributed to the brainstem and spinal cord. Such dissociation is straightforward in rats using MPTA microinjection (Abulafia et al., 2009), but in humans, microinjection is clearly impracticable. There 
might be a pharmacological approach, however, if MPTA neurons express $\mathrm{GABA}_{\mathrm{A}}-\mathrm{R}$ isoforms or other propitious receptors that can be activated using target-selective anesthetics.

\section{Conclusions}

Our results add to the growing understanding of brain-state switching in general and the neural mechanisms underlying anesthesia in particular. Most notably, they support the dedicated pathways hypothesis of general anesthesia by suggesting that systemic drug administration induces immobility, analgesia, amnesia, and LOC by a primary action in the brainstem, followed by recruitment of dedicated ascending and descending axonal pathways that secondarily modulate function in far-flung effector locations in the CNS. We have located the relevant GABA-sensitive neurons to a very small, focal population within the larger region originally designated as MPTA. This nucleus appears to constitute a key node in a network that effects brain-state switching.

The improved localization of the functionally important MPTA cluster will facilitate a more detailed characterization of the relevant neurons, including their cellular properties and functional connectivity. Of particular importance is determining whether the same neurons participate in all of the functional endpoints of anesthesia or if separate subpopulations mediate atonia, analgesia, amnesia, and LOC (Reiner et al., 2007). Heterogeneity might make it possible to recruit specific neuronal subpopulations selectively permitting, for example, surgical quality pain control without sedation or selective promotion of sleep (or alertness). The improved localization will also facilitate determination of whether the flip-flop circuit associated with GABAergic anesthesia participates in other instances of transient LOC such as fainting due to hypotension (syncope), blood gas imbalance, fear, or natural sleep (Meiri et al., 2016). Finally, the identification of a localized cluster of neurons that are intimately related to brain-state switching may provide a viable experimental lead into the circuitry that realizes conscious experience itself.

\section{References}

Abulafia R, Zalkind V, Devor M (2009) Cerebral activity during the anesthesia-like state induced by mesopontine microinjection of pentobarbital. J Neurosci 29:7053-7064. CrossRef Medline

Alkire MT, Hudetz AG, Tononi G (2008) Consciousness and anesthesia. Science 322:876-880. CrossRef Medline

Anaclet C, Ferrari L, Arrigoni E, Bass CE, Saper CB, Lu J, Fuller PM (2014) The GABAergic parafacial zone is a medullary slow wave sleep-promoting center. Nat Neurosci 17:1217-1224. CrossRef Medline

Antognini JF, Carstens E, Raines DE, eds (2003) Neural mechanisms of anesthesia. Totowa, NJ: Human Press.

Baker R, Gent TC, Yang Q, Parker S, Vyssotski AL, Wisden W, Brickley SG, Franks NP (2014) Altered activity in the central medial thalamus precedes changes in the neocortex during transitions into both sleep and propofol anesthesia. J Neurosci 34:13326-13335. CrossRef Medline

Beaumont K, Chilton WS, Yamamura HI, Enna SJ (1978) Muscimol binding in rat brain: association with synaptic GABA receptors. Brain Res 148:153-162. CrossRef Medline

Bonhomme V, Boveroux P, Brichant JF, Laureys S, Boly M (2012) Neural correlates of consciousness during general anesthesia using functional magnetic resonance imaging (fMRI). Arch Ital Biol 150:155-163. CrossRef Medline

Bremer F (1936) Nouvelles recherches sur le mecanisme du someil. CR Seances Soc Biol Fil (Paris) 122:460-464.

Brischoux F, Chakraborty S, Brierley DI, Ungless MA (2009) Phasic excitation of dopamine neurons in ventral VTA by noxious stimuli. Proc Natl Acad Sci U S A 106:4894-4899. CrossRef Medline

Brown EN, Lydic R, Schiff ND (2010) General anesthesia, sleep, and coma. N Engl J Med 363:2638-2650. CrossRef Medline

Campagna JA, Miller KW, Forman SA (2003) Mechanisms of actions of inhaled anesthetics. N Engl J Med 348:2110-2124. CrossRef Medline
Choong E, Loryan I, Lindqvist M, Nordling Å, el Bouazzaoui S, van Schaik RH, Johansson I, Jakobsson J, Ingelman-Sundberg M (2013) Sex difference in formation of propofol metabolites: a replication study. Basic Clin Pharmacol Toxicol 113:126-131. CrossRef Medline

Correa-Sales C, Rabin BC, Maze M (1992) A hypnotic response to dexmedetomidine, an alpha 2 agonist, is mediated in the locus coeruleus in rats. Anesthesiology 76:948-952. CrossRef Medline

Davies M, Thuynsma RP, Dunn SM (1998) Effects of propofol and pentobarbital on ligand binding to GABAA receptors suggest a similar mechanism of action. Can J Physiol Pharmacol 76:46-52. Medline

Devor M, Zalkind V (2001) Reversible analgesia, atonia, and loss of consciousness on bilateral intracerebral microinjection of pentobarbital. Pain 94:101-112. CrossRef Medline

Devor M, Zalkind V, Fishman Y, Minert A (2016) Model of anaesthetic induction by unilateral intracerebral microinjection of GABAergic agonists. Eur J Neurosci 43:846-858. CrossRef Medline

Folkman J, Mark VH, Ervin F, Suematsu K, Hagiwara R (1968) Intracerebral gas anesthesia by diffusion through silicone rubber. Anesthesiology 29:419-425. CrossRef Medline

Franks NP (2008) General anaesthesia: from molecular targets to neuronal pathways of sleep and arousal. Nat Rev Neurosci 9:370-386. CrossRef Medline

French JD, Verzeano M, Magoun HW (1953) A neural basis of the anesthetic state. AMA Arch Neurol Psychiatry 69:519-529. CrossRef Medline

Fuller PM, Fuller P, Sherman D, Pedersen NP, Saper CB, Lu J (2011) Reassessment of the structural basis of the ascending arousal system. J Comp Neurol 519:933-956. CrossRef Medline

Grasshoff C, Rudolph U, Antkowiak B (2005) Molecular and systemic mechanisms of general anaesthesia: the 'multi-site and multiple mechanisms' concept. Curr Opin Anaesthesiol 18:386-391. CrossRef Medline

Hentschke H, Schwarz C, Antkowiak B (2005) Neocortex is the major target of sedative concentrations of volatile anaesthetics: strong depression of firing rates and increase of GABAA receptor-mediated inhibition. Eur J Neurosci 21:93-102. CrossRef Medline

Hoymork SC, Raeder J (2005) Why do women wake up faster than men from propofol anaesthesia? Br J Anaesth 95:627-633. CrossRef Medline

Hudetz AG, Mashour GA (2016) Disconnecting consciousness: is there a common anesthetic endpoint? Anesth Analg 123:1228-1240. CrossRef Medline

Johnston GA (2014) Muscimol as an ionotropic GABA receptor agonist. Neurochem Res 39:1942-1947. CrossRef Medline

Kelz MB, Sun Y, Chen J, Cheng Meng Q, Moore JT, Veasey SC, Dixon S, Thornton M, Funato H, Yanagisawa M (2008) An essential role for orexins in emergence from general anesthesia. Proc Natl Acad Sci U S A 105:1309-1314. CrossRef Medline

Koningsmark BW (1970) Methods for the counting of neurons. In: Contemporary research methods in neuroanatomy (Nauta WJH, Ebbesson SOE, eds), pp 315-340. New York: Springer.

Löscher W, Rogawski MA (2012) How theories evolved concerning the mechanism of action of barbiturates. Epilepsia 53:12-25. CrossRef Medline

Lu J, Nelson LE, Franks N, Maze M, Chamberlin NL, Saper CB (2008) Role of endogenous sleep-wake and analgesic systems in anesthesia. J Comp Neurol 508:648-662. CrossRef Medline

Lukatch HS, MacIver MB (1996) Synaptic mechanisms of thiopentalinduced alterations in synchronized cortical activity. Anesthesiology 84: 1425-1434. CrossRef Medline

Magni F, Moruzzi G, Rossi G, Zanchetti A (1959) EEG arousal following inactivation of the lower brain stem by selective injection of barbiturate into the vertebral circulation. Arch Ital Biol 97:33-41.

Mashour GA, Hudetz AG (2017) Bottom-up and top-down mechanisms of general anesthetics modulate different dimensions of consciousness. Front Neural Circuits 11:44. CrossRef Medline

Meiri G, Lanir S, Minert A, Devor M (2016) Transient loss of consciousness during hypercapnia and hypoxia: Involvement of pathways associated with general anesthesia. Exp Neurol 284:67-78. CrossRef Medline

Minert A, Devor M (2016) Brainstem node for loss of consciousness due to GABA receptor-active anesthetics. Exp Neurol 275:38-45. CrossRef Medline

Moore JT, Chen J, Han B, Meng QC, Veasey SC, Beck SG, Kelz MB (2012) Direct activation of sleep-promoting VLPO neurons by volatile anesthetics contributes to anesthetic hypnosis. Curr Biol 22:2008-2016. CrossRef Medline 
Morales M, Margolis EB (2017) Ventral tegmental area: cellular heterogeneity, connectivity and behaviour. Nat Rev Neurosci 18:73-85. CrossRef Medline

Moruzzi G, Magoun HW (1949) Brain stem reticular formation and activation of the EEG. Electroencephalogr Clin Neurophysiol 1:455-473. CrossRef Medline

Myers R (1966) Injection of solutions into cerebral tissue: relation between volume and diffusion. Physiol Behav 1:171-174. CrossRef

Myers RD, Hoch DB (1978) 14C-dopamine microinjected into the brainstem of the rats: dispersion kinetics, site content and functional dose. Brain Res Bull 3:601-609. CrossRef Medline

Namjoshi DR, McErlane SA, Taepavarapruk N, Soja PJ (2009) Network actions of pentobarbital in the rat mesopontine tegmentum on sensory inflow through the spinothalamic tract. J Neurophysiol 102:700-713. CrossRef Medline

Paxinos G, Watson C (1998) The rat brain in stereotaxic coordinates, Ed 4. San Diego: Academic.

Paxinos G, Carrive P, Wang H, Wang PY (1999) Cytoarchitectural atlas of the rat brainstem. San Diego: Academic.

Raz A, Grady SM, Krause BM, Uhlrich DJ, Manning KA, Banks MI (2014) Preferential effect of isoflurane on top-down vs. bottom-up pathways in sensory cortex. Front Syst Neurosci 8:191. CrossRef Medline

Reiner K, Sukhotinsky I, Devor M (2007) Mesopontine tegmental anesthesia area projects independently to the rostromedial medulla and to the spinal cord. Neuroscience 146:1355-1370. CrossRef Medline

Reiner K, Sukhotinsky I, Devor M (2008) Bulbospinal neurons implicated in mesopontine-induced anesthesia are substantially collateralized. J Comp Neurol 508:418-436. CrossRef Medline

Roeder Z, Chen Q, Davis S, Carlson JD, Tupone D, Heinricher MM (2016) Parabrachial complex links pain transmission to descending pain modulation. Pain 157:2697-2708. CrossRef Medline

Scharf MT, Kelz MB (2013) Sleep and anesthesia interactions: a pharmacological appraisal. Curr Anesthesiol Rep 3:1-9. CrossRef Medline

Schiff ND, Giacino JT, Kalmar K, Victor JD, Baker K, Gerber M, Fritz B, Eisenberg B, Biondi T, O'Connor J, Kobylarz EJ, Farris S, Machado A, McCagg C, Plum F, Fins JJ, Rezai AR (2007) Behavioural improvements with thalamic stimulation after severe traumatic brain injury. Nature 448: 600-603. CrossRef Medline

Sherman D, Fuller PM, Marcus J, Yu J, Zhang P, Chamberlin NL, Saper CB, $\mathrm{Lu} \mathrm{J}$ (2015) Anatomical location of the mesencephalic locomotor region and its possible role in locomotion, posture, cataplexy and parkinsonism. Front Neurol 6:140. CrossRef Medline

Shik ML, Severin FV, Orlovsky GN (1969) Control of walking and running by means of electrical stimulation of the mesencephalon. Electroencephalogr Clin Neurophysiol 26:549. Medline
Sleigh JW, Steyn-Ross DA, Steyn-Ross ML, Williams ML, Smith P (2001) Comparison of changes in electroencephalographic measures during induction of general anaesthesia: influence of the gamma frequency band and electromyogram signal. Br J Anaesth 86:50-58. CrossRef Medline

Sukhotinsky I, Zalkind V, Devor M (2003) Anesthetic effect of barbiturates microinjected into the brainstem: neuroanatomy. In: Proccedings of the 10th world congress on pain (Dostrovsky J, Carr D, Koltzenburg M, eds), pp 305-313. Seattle: IASP.

Sukhotinsky I, Zalkind V, Lu J, Hopkins DA, Saper CB, Devor M (2007) Neural pathways associated with loss of consciousness caused by intracerebral microinjection of GABA A-active anesthetics. Eur J Neurosci 25: 1417-1436. CrossRef Medline

Sukhotinsky I, Minert A, Soja P, Devor M (2016) Mesopontine switch for the induction of general anesthesia by dedicated neural pathways. Anesth Analg 123:1274-1285. CrossRef Medline

Taylor NE, Van Dort CJ, Kenny JD, Pei J, Guidera JA, Vlasov KY, Lee JT, Boyden ES, Brown EN, Solt K (2016) Optogenetic activation of dopamine neurons in the ventral tegmental area induces reanimation from general anesthesia. Proc Natl Acad Sci U S A.

Tononi G, Boly M, Massimini M, Koch C (2016) Integrated information theory: from consciousness to its physical substrate. Nat Rev Neurosci 17:450-461. CrossRef Medline

Vijayan S, Ching S, Purdon PL, Brown EN, Kopell NJ (2013) Thalamocortical mechanisms for the anteriorization of alpha rhythms during propofol-induced unconsciousness. J Neurosci 33:11070-11075. CrossRef Medline

Voss LJ, Young BJ, Barnards JP, Sleigh J (2005) Differential anaesthetic effects following microinjection of thiopentone and propofol into the pons of adult rats: a pilot study. Anaesth Intensive Care 33:373-380. Medline

Watson CJ, Lydic R, Baghdoyan HA (2011) Sleep duration varies as a function of glutamate and GABA in rat pontine reticular formation. J Neurochem 118:571-580. CrossRef Medline

Weber F, Chung S, Beier KT, Xu M, Luo L, Dan Y (2015) Control of REM sleep by ventral medulla GABAergic neurons. Nature 526:435-438. CrossRef Medline

Xi MC, Morales FR, Chase MH (2001) Induction of wakefulness and inhibition of active (REM) sleep by GABAergic processes in the nucleus pontis oralis. Arch Ital Biol 139:125-145. Medline

Zecharia AY, Yu X, Götz T, Ye Z, Carr DR, Wulff P, Bettler B, Vyssotski AL, Brickley SG, Franks NP, Wisden W (2012) GABAergic inhibition of histaminergic neurons regulates active waking but not the sleep-wake switch or propofol-induced loss of consciousness. J Neurosci 32:13062-13075. CrossRef Medline 